\title{
Persistence of Mild Hyperthyrotropinemia after Discontinuation of Three-Year Course of Low-Dose L-Thyroxine Therapy in Infants with Borderline Hypothyroidism
}

\author{
YUICHIRO TOMITA, HIROYUKI ISHIGURO, TSUYOSHI SHINAGAWA, CHIDORI KUBOTA \\ AND OSAMU SHINOHARA
}

Department of Pediatrics, Tokai University School of Medicine, Isehara, Kanagawa 259-1193, Japan

\begin{abstract}
Treatment plan for neonates with borderline hypothyroidism (persistent hyperthyrotropinemia with normothyroxinemia) has not been established. In this study, changes in thyroid function after discontinuation of low-dose L-thyroxine (L-T4) supplement in infants with the condition were evaluated. Fourteen infants with hyperthyrotropinemia at neonatal screening had repeated hyperthyrotropinemia $(>8 \mathrm{mU} / \mathrm{L})$ with normothyroxinemia. TSH response was exaggerated at TRH testing. The subjects were treated with low-dose L-T4 (3 to $9 \mu \mathrm{g} / \mathrm{kg} / \mathrm{day}$ ) for 2.2 to 6 years, and euthyroid status was maintained. After discontinuation of therapy, mild hyperthyrotropinemia persisted up to 24 months, while serum FT4 remained within the lower half of the normal range. TSH response to TRH stimulation, which tended to be exaggerated 1 month after discontinuation, became lower 6 to 12 months later. RAIU and thyroid scintigraphy were normal in all subjects. No patient developed hypothyroxinemia, although mild elevation of TSH lasted rather long after discontinuation of low-dose L-T4 therapy. Administration of L-T4 was not resumed provided the subjects were followed at regular interval. Further long-term investigation is needed to define whether re-administration is necessary or not.
\end{abstract}

Key words: Congenital hypothyroidism, Hyperthyrotropinemia, Thyroid hormone therapy, TRH test, Neonatal screening

(Endocrine Journal 50: 379-384, 2003)

SINCE the introduction of neonatal screening for congenital hypothyroidism, patients with this disorder scarcely suffer from physical underdevelopment or mental retardation. As the number of cases who receive neonatal screening is accumulating, we often encounter infants who continue to have mildly elevated serum TSH levels without having low serum FT4 concentrations (borderline hypothyroidism). However, there is no consensus concerning the follow-up or treatment plan for borderline hypothyroidism in infancy. Recent study advocates the administration of lowdose L-thyroxine (L-T4) to the infants with borderline hypothyroidism to prevent possible adverse effect of

Received: November 11, 2002

Accepted: March 25, 2003

Correspondence to: Osamu SHINOHARA, M.D., Department of Pediatrics, Tokai University School of Medicine Bohseidai, Isehara, Kanagawa 259-1193, Japan mild hypothyroidism on the developing brain [1].

We previously encountered an infant with persistent mild hyperthyrotropinemia with normal FT4 levels who was finally diagnosed to have definite congenital hypothyroidism due to ectopic thyroid at the age of 1.5 years. Hunter et al. also described the occurrence of delayed TSH rise [2]. Hence, it is our current practice to treat those with borderline hypothyroidism with low dose L-T4 regimen for 3 years and finalize the diagnosis thereafter. The aim of this communication is to present the changes in thyroid function after discontinuation of low-dose L-T4 supplement in the patients with borderline hypothyroidism in infancy.

\section{Subjects And Methods}

Fourteen subjects ( 9 males and 5 females) met the criteria of borderline hypothyroidism (as described 
below), and were included in this study. The subjects were born after 36 to 40 weeks of gestation with birth weight from 2090 to $3580 \mathrm{~g}$. Pregnancy and delivery were uneventful, and no mother had thyroid disorder or iodide administration during pregnancy. One infant had Down syndrome. All infants received neonatal screening test at the age of 5 to 7 days. The age at the first visit to our clinic ranged from 13 to 64 days.

\section{Protocol for Evaluation of Neonates who Showed Abnormal Screening Results}

Thyroid function test at neonatal screening included TSH and FT4. Neonates whose TSH levels exceeded $15 \mathrm{mU} / \mathrm{L}$ at screening were recalled for confirmatory test and referred to our clinic no matter what their FT4 concentrations were. Those with low FT4 at screening were immediately treated with L-T4, and excluded from the study. Infants whose serum TSH concentrations were $>30 \mathrm{mU} / \mathrm{L}$ received L-T4 supplement even if their FT4 levels were within normal range. For those who showed mild hyperthyrotropinemia (TSH 8 to $30 \mathrm{mU} / \mathrm{L}$ ) more than twice, TRH stimulation test was performed. Children with normal FT4 levels whose basal TSH levels were repeatedly greater than $8 \mathrm{mU} / \mathrm{L}$ and/or whose peak TSH response exceeded $40 \mathrm{mU} / \mathrm{L}$ were defined to have borderline hypothyroidism, and low-dose L-T4 therapy (3 to $9 \mu \mathrm{g} / \mathrm{kg} /$ day) was initiated. Some of the subjects with mild hyperthyrotropinemia defined as above received low-dose L-T4 without having TRH test.

The subjects received L-T4 replacement from 3 to 8 weeks of age for 2.2 to 6 years at a dose that kept their serum TSH and FT4 levels within the normal range. The subjects were followed up every month until 1 year of age, and every 2 to 3 months thereafter. The dosage of L-T4 was increased in those whose serum TSH became constantly $>10 \mathrm{mU} / \mathrm{L}$ during treatment. In most cases, the dosage ranged from 2 to $3 \mu \mathrm{g} / \mathrm{kg} /$ day at the end of treatment. At the time of initiation and discontinuation of L-T4 replacement, we informed the parents about the nature of the study closely, and the parents agreed to the whole process.

One to 2 months after discontinuation of L-T4 supplement, the subject underwent re-evaluation of thyroid function by TRH stimulation test, thyroid scanning, and radioactive iodine uptake (RAIU). Determination of basal serum FT4 and TSH concentration was repeated every 3 to 4 months thereafter for 9 to 48 months.

\section{TRH Stimulation Test}

TRH $\left(300 \mu \mathrm{g} / \mathrm{m}^{2}\right)$ was given i.v. after basal blood sampling from an indwelling venous catheter. For initial evaluation at neonatal period, blood sample was drawn before and $30 \mathrm{~min}$ after TRH injection for the measurement of TSH. At re-evaluation after discontinuation of L-T4 supplement, blood was drawn every 30 min until $120 \mathrm{~min}$ after TRH loading. Serum TSH, FT4, and FT3 concentrations were measured by chemiluminescent enzyme immunoassay. Since no reference data on TSH response to TRH during neonatal period was available, mean $+/-$ SD levels obtained from the data of children aged 3 to 6 years at our institute was plotted in the figure.

\section{Thyroid Scintigraphy and Radioactive Iodine Uptake (RAIU)}

Radioactive iodine (123-I) was given at a dose of $0.1 \mathrm{MBq} / \mathrm{kg}$, followed by a scintigraphy $24 \mathrm{~h}$ later.

\section{Results}

Fig. 1 shows serum TSH levels before L-T4 supplement. At neonatal screening, TSH levels ranged from

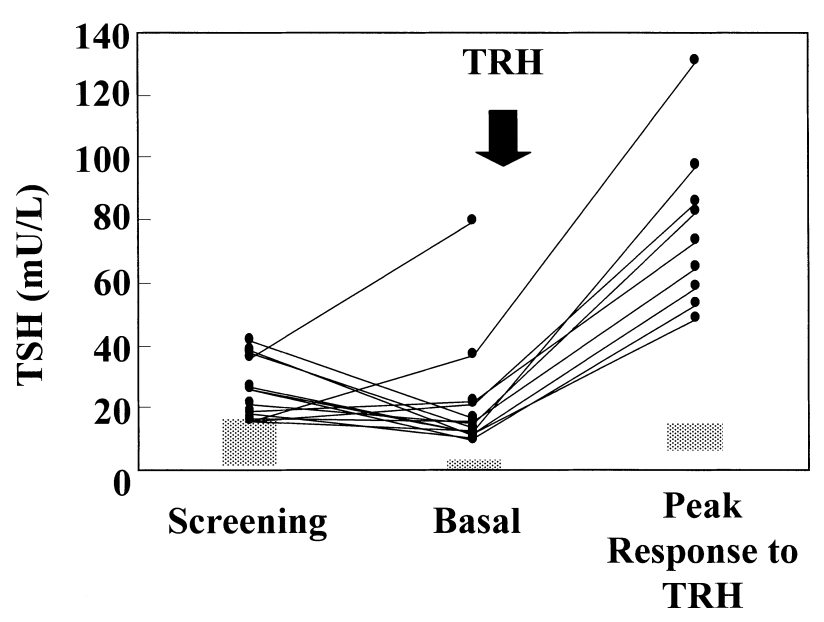

Fig. 1. Serum TSH levels before L-T4 supplement. Blood TSH levels at neonatal screening (left), basal TSH at confirmatory testing (middle), and peak response (right) after TRH stimulation. Shaded boxes show mean $+/-$ 2SD. The range for peak TSH response to TRH is for children aged 3 to 6 years. 
15.6 to $41.0 \mathrm{mU} / \mathrm{L}$ (Fig. 1, left), and FT4 levels were from 1.3 to $2.0 \mathrm{ng} / \mathrm{dL}$ (not shown). At confirmatory tests, serum TSH concentrations ranged from 9.1 to $79.2 \mathrm{mU} / \mathrm{L}$ (median, 14.0; Fig. 1, center), and FT4 levels were from 1.08 to $1.74 \mathrm{ng} / \mathrm{dL}$ (median, 1.53). TSH responses $30 \mathrm{~min}$ after TRH stimulation ranged from 48.6 to $131.0 \mathrm{mU} / \mathrm{L}$ (median, 72.8; Fig. 1, right).

The subjects were treated with low-dose L-T4 as described, and changes in thyroid function were evaluated. During L-T4 treatment, serum FT4 levels remained in the upper half of the normal range (Fig. 2, left). One month after discontinuation of L-T4, median FT4 concentration declined slightly to $1.22 \mathrm{ng} / \mathrm{dL}$, and stayed in the lower half of the normal range thereafter (Fig. 2, right). No patient had hypothyroxinemia.
Changes in basal serum TSH levels during L-T4 supplement and after discontinuation are shown in Fig. 3. Basal TSH rapidly decreased to the normal range after the first month of L-T4 therapy, and remained in the normal range during supplement (Fig. 3, left). Although median TSH concentration increased slightly to $6.20 \mathrm{mU} / \mathrm{L}$ one month after discontinuation of L-T4, it became slightly decreased toward 24 months after discontinuation (Fig. 3, right); median TSH concentrations $6,12,18$, and 24 month after discontinuation were $6.84,6.18,5.51$, and $4.67 \mathrm{mU} / \mathrm{L}$, respectively. One subject experienced elevated basal TSH up to $17.70 \mathrm{mU} / \mathrm{L}$ at 9 months after discontinuation. His FT4 levels remained in the normal range, and serum TSH levels gradually decreased to the range of 5 to

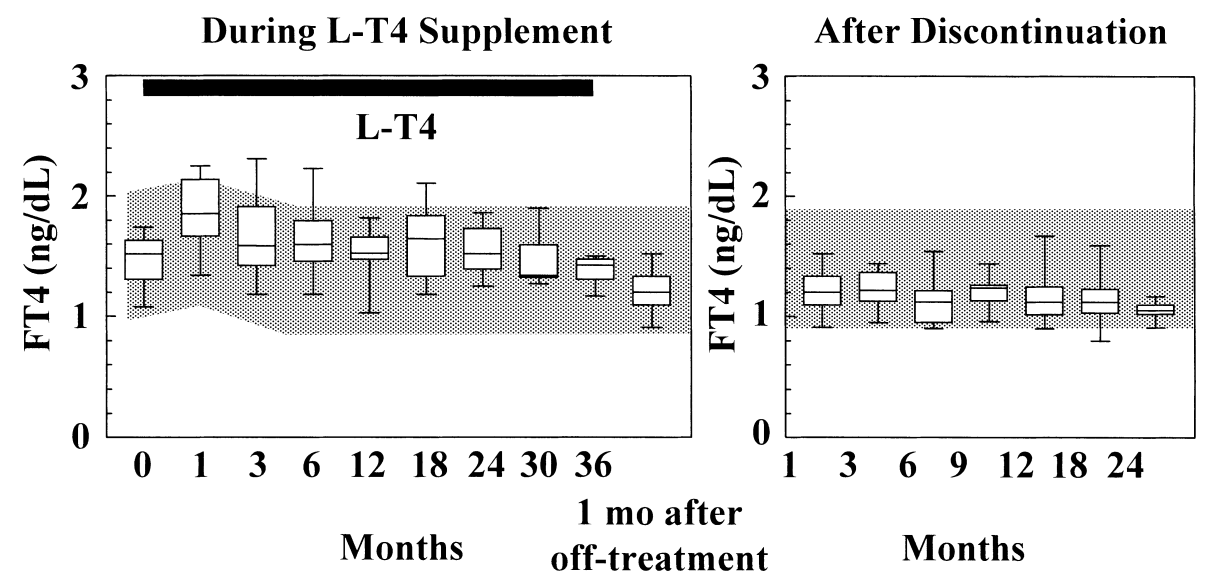

Fig. 2. Changes in serum FT4 levels during (left) and after discontinuation of (right) L-T4 supplement. Shaded area shows the normal range. The lower and upper boundary of the box shows the 25th and 75th percentile, respectively. The top and bottom of the bar show maximum and minimal value, respectively.

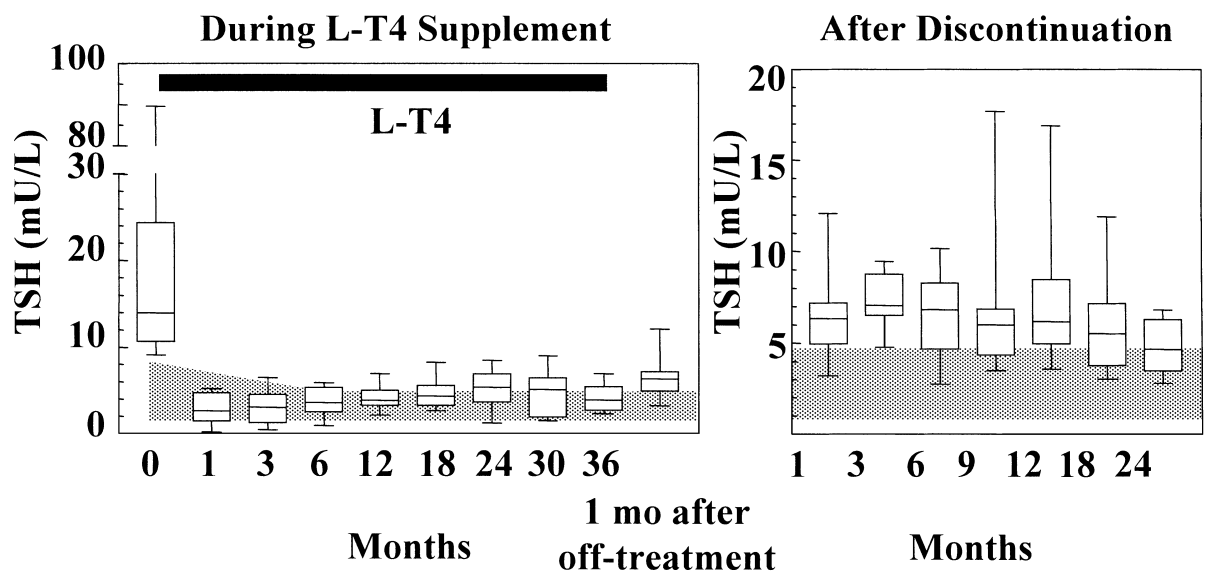

Fig. 3. Changes in basal serum TSH levels during (left) and after discontinuation of (right) L-T4 supplement. Shaded area shows the normal range. The lower and upper boundaries of the box show the 25 th and 75 th percentile, respectively. The top and bottom of the bar show maximum and minimal value, respectively. 


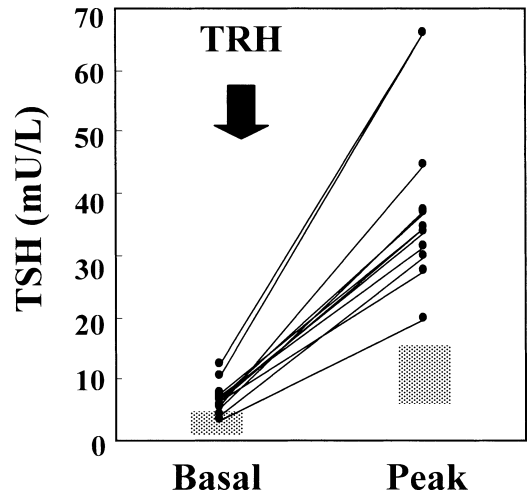

Fig. 4. Response of TSH to TRH stimulation 1 month after discontinuation of L-T4 supplement. The range for peak TSH response to TRH is for children aged 3 to 6 years.

$7 \mathrm{mU} / \mathrm{L}$ thereafter (not shown), showing the transient nature of hyperthyrotropinemia.

Changes in TSH response to TRH stimulation after discontinuation of L-T4 supplement are shown in Fig. 4. Twelve subjects underwent a TRH test one month after discontinuation. Basal TSH ranged from 2.8 to $12.1 \mathrm{mU} / \mathrm{L}$, and peak levels were from 19.6 to $65.7 \mathrm{mU} / \mathrm{L}$.

RAIU, which was performed in 12 subjects, ranged from 7.9 to $40.5 \%$ at 24 hours. Perchlorate discharge test was not performed. The positioning and the shape of the thyroid gland were normal in all subjects tested by thyroid scintigraphy. None of the subjects had physical underdevelopment, and none except one with Down syndrome had delay in intellectual development as checked by Japanese Denver Developmental Screening Test, although exact IQ testing was not performed in the current study. No clinical signs or symptoms corresponding to excessive L-T4 treatment were observed while the subjects were receiving L-T4. L-T4 therapy was not restarted in any of the subjects.

\section{Discussion}

We found that most of the subjects with borderline hypothyroidism continued to have mild elevation of basal serum TSH levels as well as peak response to TRH stimulation after discontinuation of low-dose LT4 supplement. Serum FT4 concentration became slightly decreased and remained within the lower half of the normal range up to 24 months after discontinuation. No patient developed hypothyroidism or hypo- thyroxinemia.

Avoidance of mental retardation and physical underdevelopment is the goal of neonatal screening for congenital hypothyroidism. Previous studies have shown that that improved intellectual ability can be expected by starting with large dose of L-T4 at an early age $[3,4]$. Song et al. reported that earlier normalization of hyperthyrotropinemia in patients with congenital hypothyroidism resulted in better intellectual outcome during childhood [5]. Current recommendation is to treat the patients with congenital hypothyroidism with 10 to $15 \mu \mathrm{g} / \mathrm{kg} / \mathrm{d}$ of L-T4 as early as possible to prevent psychomotor retardation [6]. For the children with hypothyroidism, the Japanese Society for Pediatric Endocrinology recommends giving 5 to $7 \mu \mathrm{g} / \mathrm{kg} / \mathrm{d}$ at the age of 1 to 5 years [7], hence the dosage applied in our study is less than this recommendation. As for follow-up treatment, Raza et al. reported that maintaining serum FT4 levels within the normal range, regardless of TSH concentration, is the safest approach in treating congenital hypothyroidism [8].

Concerning mild hyperthyrotropinemia, significance of the condition has been the matter of debate over the years in the adult. Although deleterious effects on cardiovascular function or on lipid profile have been reported [9-11], there is a controversy about thyroid replacement in the patients with subclinical hypothyroidism $[12,13]$. As for neonates with continuous hyperthyrotropinemia, no consensus has been reached whether to treat or not.

In the neonate, whether borderline hypothyroidism is regarded as a risk factor for impaired intellectual outcome and should be treated is controversial. However, it should be kept in mind that mental retardation caused by hypothyroidism is irreversible in the infant, while many other conditions in the adult hypothyroidism can be reversed by thyroid replacement. Hence, subtle changes in thyroid function should not be overlooked.

Most infants with mild elevations of TSH at screening show normal results at confirmatory test. However, we previously experienced a patient who was diagnosed to have definite congenital hypothyroidism after 1 year of age. The infant initially showed borderline hypothyroidism, and while on low-dose L-T4 replacement, his basal TSH levels gradually increased to $75 \mathrm{mU} / \mathrm{L}$ at 1.5 year of age, and the dose had to be increased. The patient was later found to have ectopic thyroid while on L-T4 therapy, and has been physical- 
ly and intellectually normal. The patients like this case may suffer from irreversible damage to the developing brain, if they are left untreated from early infancy or if there is a delay in initiation of replacement therapy. Hunter et al. also described the patients with "delayed TSH rise" in a large-scale survey [2]. From the aforementioned experience and this report, we believe that infants who repeatedly show mild hyperthyrotropinemia with normal FT4 levels should not be regarded as "transient elevation in serum TSH of the neonates" and left untreated without close observation. Currently it is our practice to give low-dose L-T4 $(5 \mu \mathrm{g} / \mathrm{kg} / \mathrm{d})$ to infants with borderline hypothyroidism. Obviously, overtreatment with L-T4 should be strictly avoided since difficulty in behavior could occur if the patients are kept in the hyperthyroid state.

Our protocol resembles the one that was reported recently by Daliva et al. [1]. The difference is that they resumed L-T4 supplement to those whose serum TSH levels exceeded $4.6 \mathrm{mU} / \mathrm{L}$ after discontinuation of $\mathrm{L}$ T4 supplement. We did not resume treatment and closely monitored thyroid function. Whether to restart L-T4 therapy is a matter of debate that remains to be solved. No patient developed hypothyroxinemia, and none developed continuous overt hyperthyrotropinemia ( $>10 \mathrm{mU} / \mathrm{L})$, although basal TSH levels were slightly elevated at a range of 5 to $10 \mathrm{mU} / \mathrm{L}$ in most of the subjects. Whether this mild elevation in serum TSH should be regarded as mild thyroid failure is uncertain at the time of this writing. While we have not performed testing for developmental or intelligent quotient, no children experienced mental or physical underdevelopment except for one patient with Down syndrome. Another drawback of this prospective study is that organification defect cannot be detected without perchlorate discharge test. We plan to perform the test for those who continuously exhibit hyperthyrotropinemia.

In conclusion, mild elevation of basal TSH persisted up to 24 months after discontinuation of supplement with 3- to 6-year course of low-dose L-T4 supplement. Since no data concerning intellectual development among mild neonatal hyperthyrotropinemia exist and overt biochemical changes may not appear during neonatal period in the rare patient with congenital hypothyroidism, we advocate the administration of low-dose L-T4 therapy in neonates with borderline hypothyroidism. We did not resume the administration of L-T4 provided that the thyroid function of these children is followed at a regular interval and the FT4 levels remain within the normal range. Further long-term investigation is needed to define whether re-administration is necessary or not.

\section{References}

1. Daliva AL, Linder B, DiMartino-Nardi J, Saenger P (2000) Three-year follow-up of borderline congenital hypothyroidism. J Pediatr 136: 53-56.

2. Hunter MK, Mandel SH, Sesser DE, Miyahira RS, Rien L, Skeels MR, Lafranchi SH (1998) Follow-up of newborns with low thyroxine and nonelevated thyroidstimulating hormone-screening concentrations: Results of the 20-year experience in the northwest regional newborn screening program. $J$ Pediatr 132: 70-74.

3. Salerno M, Militerni R, Bravaccio C, Micillo M, Capalbo D, Di MS, Tenore A (2002) Effect of different starting doses of levothyroxine on growth and intellectual outcome at four years of age in congenital hypothyroidism. Thyroid 12: 45-52.

4. Bongers-Schokking JJ (2001) Pre- and postnatal brain development in neonates with congenital hypothyroidism. J Pediatr Endocrinol Metab 14 Suppl 6: 14631468.

5. Song SI, Daneman D, Rovet J (2001) The influence of etiology and treatment factors on intellectual outcome in congenital hypothyroidism. J Dev Behav Pediatr 22: 376-384.

6. Fisher DA (2002) Disorders of the thyroid in the newborn and infant. In: Sperling MA (ed) Pediatric Endocrinology, 2nd ed., Saunders, Philadelphia: 161-185.

7. Inomata $\mathrm{H}$, Matsuura $\mathrm{N}$, Tachibana $\mathrm{K}$, Kusuda $\mathrm{S}$, Fukushi M, Umehashi H, Suwa S, Niimi H, Fujieda K (1999) Guideline for neonatal mass-screening for congenital hypothyroidism. Clin Pediatr Endocrinol 8: $51-55$.

8. Raza J, Hindmarsh PC, Brook CGD (1997) Factors involved in the rate of fall of thyroid stimulating hormone in treated hypothyroidism. Arch Dis Child 77: 526-527.

9. Kahaly GJ (2000) Cardiovascular and atherogenic aspects of subclinical hypothyroidism. Thyroid 10: 665679.

10. Hak AE, Pols HA, Visser TJ, Drexhage HA, Hofman A, Witteman JC (2000) Subclinical hypothyroidism is an independent risk factor for atherosclerosis and myo- 
cardial infarction in elderly women: the Rotterdam Study. Ann Intern Med 132: 270-278.

11. Danese MD, Ladenson PW, Meinert CL, Powe NR (2000) Clinical review 115: effect of thyroxine theraphy on serum lipoproteins in patients with mild thyroid failure; a quantitative review of the literature. J Clin Endocrinol Metab 85: 2993-3001.
12. McDermott MT, Ridgway EC (2001) Subclinical hypothyroidism is mild thyroid failure and should be treated. J Clin Endocrinol Metab 86: 4585-4590.

13. Chu JW, Crapo LM (2001) The treatment of subclinical hypothyroidism is seldom necessary. J Clin Endocrinol Metab 86: 4591-4599. 